\title{
Magnetic compression anastomosis for biliary obstruction after partial hepatectomy
}

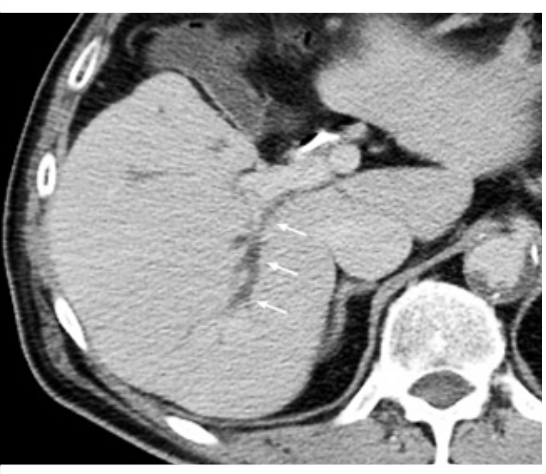

- Fig. 1 Dilatation of the right-posterior intrahepatic bile (arrows) seen at computed tomography (CT).

Magnetic compression anastomosis (MCA) is a revolutionary method of performing choledochocholedochostomy without surgery in patients with biliary obstruction [1-5]. Herein, we report the successful treatment, using MCA, of a case of complete biliary obstruction after partial hepatectomy.

A 64-year-old man who had undergone right partial hepatectomy for a metastatic liver tumor from rectal cancer was admitted to another hospital with bile leakage. Although the bile leakage was treated by endoscopic nasobiliary drainage, there was prolonged liver dysfunction, and computed tomography showed dilatation of the right-posterior intrahepatic bile duct ( $\triangleright$ Fig.1). Endoscopic retrograde cholangiopancreatography and percutaneous transhepatic biliary drainage (PTBD) were attempted but recanalization was not possible ( $\mathbf{F i g . 2}$ ). Therefore, the patient was referred to our hospital.

Initially, an 18-Fr PTBD catheter was placed. A cylindrical neodymium magnet, $5 \mathrm{~mm}$ in diameter, was pushed to the tip of the PTBD catheter and inserted in the intrahepatic bile duct using biopsy forceps ( $\triangleright$ Video 1$)$. Next, another magnet, $3 \mathrm{~mm}$ in diameter, was inserted up to the tip of the inner part of the outer sheath of the guidewire (VisiGlide 2; Olympus, Tokyo, Japan) for delivery
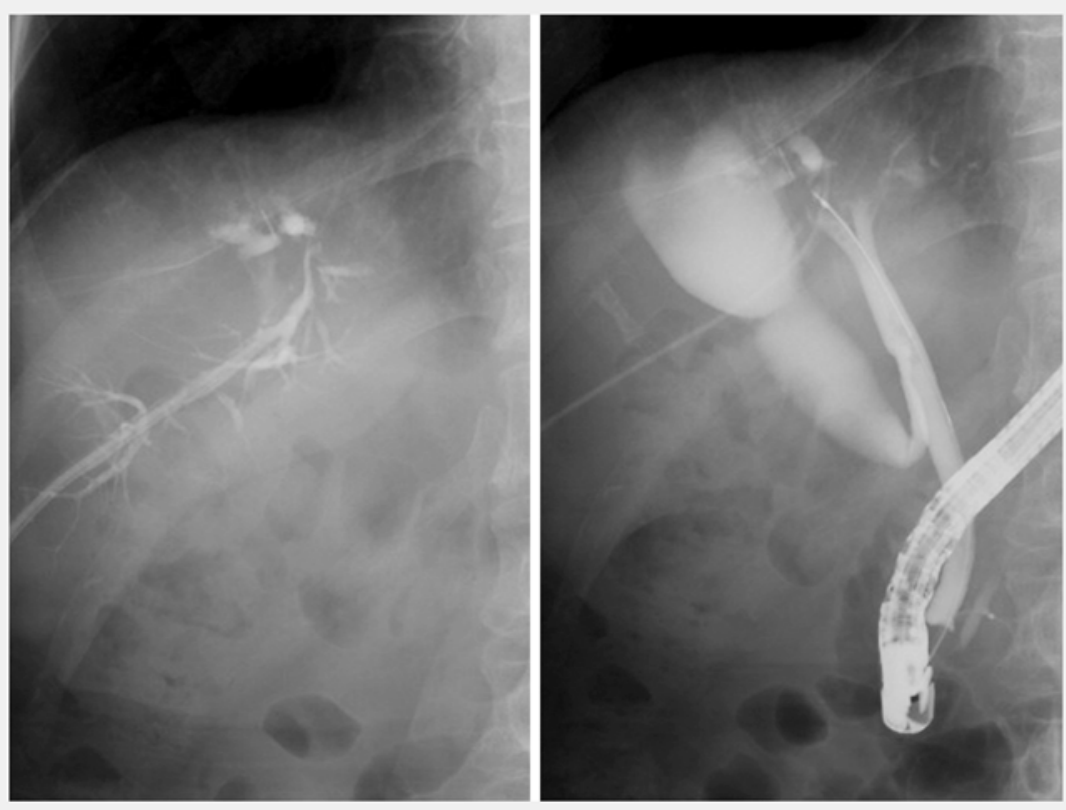

- Fig. 2 Endoscopic retrograde cholangiopancreatography and percutaneous transhepatic biliary drainage were attempted but recanalization was not possible.
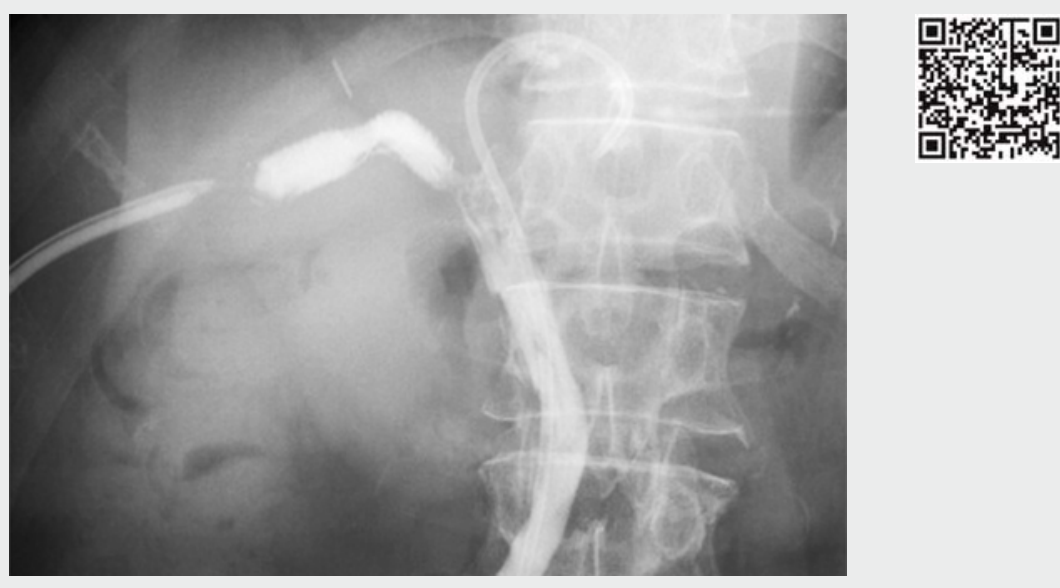

Video 1 Magnetic compression anastomosis for biliary obstruction following partial hepatectomy, after failure of recanalization by means of endoscopic retrograde cholangiopancreatography and percutaneous transhepatic biliary drainage.

( Fig.3). Then, the outer sheath with the magnet was inserted via the papilla and the magnet was pushed out using biopsy forceps. The magnets were ad- vanced to sites immediately before and after the obstruction. Then, the two magnets were positioned so that they attracted each other ( $>$ Fig. 4, $\triangleright$ Video 1). A plas- 


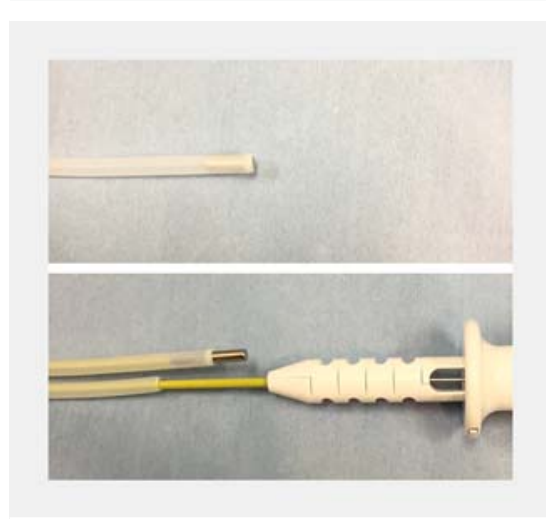

Fig. 3 A magnet was inserted up to the tip of the lumen of the outer sheath of the guidewire for delivery.

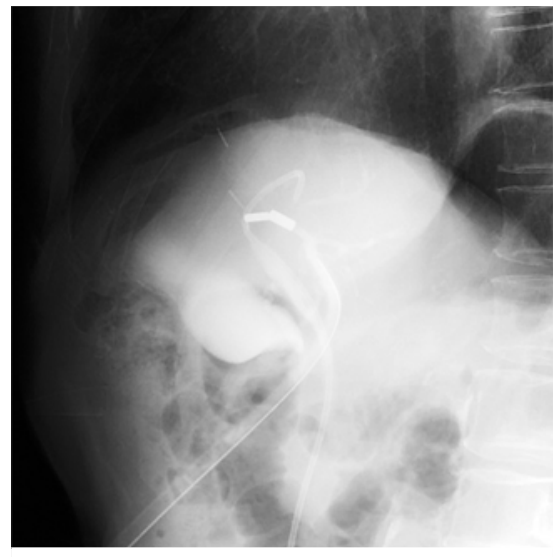

- Fig. 4 The two magnets attracted each other.

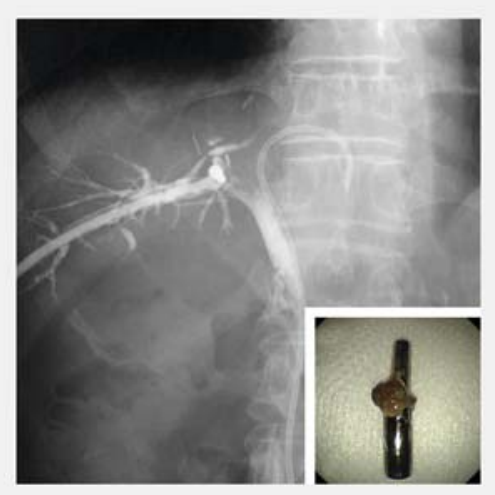

- Fig. 5 Recanalization was achieved (main figure) and the magnets were endoscopically removed (inset).

\section{Bibliography}

DOI https://doi.org/10.1055/a-0588-4653

Published online: 9.4.2018

Endoscopy 2018; 50: E144-E145

(c) Georg Thieme Verlag KG

Stuttgart · New York

ISSN 0013-726X

Japan

Fax: +81-3-53816654

ken.yamamoto5544@gmail.com

\section{References}

[1] Mimuro A, Tsuchida A, Yamanouchi E et al. A novel technique of magnetic compression anastomosis for severe biliary stenosis. Gastrointest Endosc 2003; 58: $283-287$

[2] Itoi T, Yamanouchi E, Ikeda T et al. Magnetic compression anastomosis: a novel technique for canalization of severe hilar bile duct strictures. Endoscopy 2005; 37: 1248 1251

[3] Itoi T, Yamanouchi E, Ikeuchi N et al. Magnetic compression duct-to-duct anastomosis for biliary obstruction in a patient with living donor liver transplantation. Gut Liver 2010; 4: $96-98$

[4] Itoi T, Kasuya K, Sofuni A et al. Magnetic compression anastomosis for biliary obstruction: review and experience at Tokyo Medical University Hospital. J Hepatobiliary Pancreat Sci 2011; 18: 357-365

[5] Jang SI, Kim JH, Won JY et al. Magnetic compression anastomosis is useful in biliary anastomotic strictures after living donor liver transplantation. Gastrointest Endosc 2011; 74: $1040-1048$ https://eref.thieme.de/e-videos

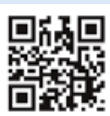

Endoscopy E-Videos is a free access online section, reporting on interesting cases and new techniques in gastroenterological endoscopy. All papers include a high quality video and all contributions are freely accessible online.

This section has its own submission website at https://mc.manuscriptcentral.com/e-videos

\section{ENDOSCOPY E-VIDEOS}

Xue-Mei jiang1', Kenjiro Yamamoto², Shuntaro Mukai ${ }^{2}$, Yuichi Nagakawa ${ }^{3}$, Takao Itoi $^{2}$

1 Department of Gastroenterology, Central South University Xiangya School of Medicine Affiliated Haikou Hospital, Haikou, China

2 Department of Gastroenterology and Hepatology, Tokyo Medical University, Tokyo, Japan

3 Third Department of Surgery, Tokyo Medical University, Tokyo, Japan 